\title{
Effect of the Intake Valve Opening Timings and Fuel Injection Pressures on the Exhaust Emission Characteristics of a Gasoline Engine at Part Load Condition
}

\author{
Hyung-Min Lee ${ }^{\dagger} \cdot$ Yeon-Hwan Jeong ${ }^{1}$
}

(Received November 29, 2010; Revised February 9, 2011; Accepted February 25, 2011)

\begin{abstract}
This work has investigated the exhaust emissions such as Total Hydrocarbon (THC), Nitrogen Oxides(NOx), and Particulate Matter (PM) characteristics emitted from the tail-pipe of a continuously variable valve timing (CVVT) gasoline-fueled engine with different intake valve opening timings and injection pressures at the part load condition. Valve overlap period was varied from $40^{\circ} \mathrm{CA}$ to $10^{\circ} \mathrm{CA}$ and fuel injection pressure was increased from 3.5 bar to 5.0 bar. THC and NOx emissions decreased as intake valve opening timing was advanced regardless of fuel injection pressure. When the fuel was injected with the condition of 5.0 bar at all of valve overlap ranges, THC levels were reduced by 55\%. NOx concentrations were diminished about $75 \%$ as valve overlap increased. PM size distributions were analyzed as bi-modal type of the nucleation and accumulation mode. Comparing with fuel injection pressures, PM emission levels were decreased at high pressure injection of 5.0 bar condition.
\end{abstract}

Key words : Continuously variable valve timing, Total hydrocarbon, Nitrogen oxides, Particulate matter, Nucleation mode, Accumulation mode

\section{Introduction}

Recently, significant efforts have been weighted toward the development of environmental friendly engines in the automotive because the mobile source has been greatly attributed to atmospheric pollutions and social problems [1].

The object for atmospheric environment of the developed countries has been focused on the effect of a variety of airborne particulate matter on the health risk [2].

The ultra-clean emission regulations such as the partial zero emissions vehicle (PZEV) demand the reduction of over $90 \%$ in tail-pipe emissions of hydrocarbon (HC) and nitrogen oxides (NOx) from present vehicles [3].

To improve these problems, continuously variable valve timing (CVVT) system is widely adopted as it can strengthen engine performance, while simultaneously diminishing exhaust emissions and increasing fuel economy. With the CVVT system of intake camshaft phaser, maximum torque and power are improved through the optimization of valve timing with respect to the overall engine operating condition [4].

Advanced intake valve opening is worked on internal EGR (Exhaust Gas Recirculation) function so that it leads to reduce the NOx emissions at the part load. In addition, the fuel injection pressure

\footnotetext{
† Corresponding Author (Department of Naval Ship Propulsion Engineering, Republic of Korea Naval Academy) E-mail: hmsj1226@korea.ac.kr, Tel: 055-549-1443

1 Department of Mechanical Engineering and Naval Architecture, Republic of Korea Naval Academy
} 
was boosted to 5.0 bar over the standard practice of 3.5 bar for the baseline engine in BMW to reduce HC emissions [5].

Generally, it has been recognized that particulate matter is mostly emitted by the diesel engine. Recent studies have announced that diesel engines emit significantly higher concentrations of particulate mass than gasoline engines. However, the total number of vehicle miles traveled by gasoline-fueled vehicles in urban areas greatly exceeds that of diesels, in which case, gasoline vehicles may contribute up to $68 \%$ of the vehicle engine-generated particulate mass and $90 \%$ of the particulate number [6].

The objective of this research is to verify the THC, NOx, and particle number concentration for different intake valve timings and fuel injection pressures at the part load condition of a gasoline-powered SI engine.

\section{Experimental Apparatus and Instruments}

Figure 1 shows the schematic diagram of the experimental apparatus used to measure the exhaust emissions at the part load condition (2,400 rpm, bmep 2.5 bar) under different fuel injection pressure (3.5 bar, 5.0 bar).

The test engine used in this study is the DOHC (Double Overhead Camshaft), in-line four cylinders, 2.0L gasoline-fueled SI engine. The experimental engine is equipped with a modern CVVT production engine, the conventional port fuel injection type with a returnless fuel rail and injectors.

The detailed engine specifications are given in Table 1. Fuel injection pressure is constantly controlled to 3.5 bar by the pressure regulator installed inside the fuel pump into fuel tank and maintained through the fuel supply line.

In addition to the above system, another fuel pump and a pressure regulator were set up on the fuel supply system to analyze the effect of the high injection pressure condition of 5.0 bar on the emission characteristics.

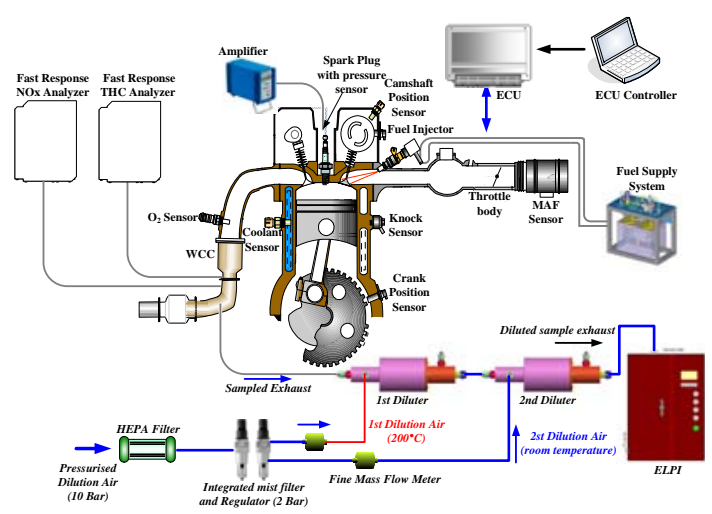

Figure 1: Schematic diagram of experimental system

The engine was controlled by the application ECU (Electronic Control Unit), a HEGO (Heated Exhaust Gas Oxygen) sensor, and air flow sensor were used to determine the control strategy of the close loop fuel control at the start phase included the transient condition. The steady operation, however, was conducted without a HEGO sensor signal to keep the open-loop state.

Table 1: Specifications of test engine

\begin{tabular}{|c|c|c|c|c|}
\hline Engine Type & \multicolumn{3}{|c|}{ In-line, DOHC 16V } \\
\hline Displacement & \multicolumn{3}{|c|}{$1,998 \mathrm{cc}$} \\
\hline Bore×Stroke & \multicolumn{3}{|c|}{$86 \mathrm{~mm} \times 86 \mathrm{~mm}$} \\
\hline Compression ratio & \multicolumn{4}{|c|}{$10.5: 1$} \\
\hline Fuel Injection & \multicolumn{3}{|c|}{ Multi Point Injection } \\
\hline Exhaust System & \multicolumn{3}{|c|}{ Warm-up Catalytic Converter } \\
\hline \multirow{3}{*}{ Valve Timing } & IVO & IVC & EVO & EVC \\
\cline { 2 - 5 } & Variable & Variable & BBDC & ATDC \\
& & & $34^{\circ} \mathrm{CA}$ & $10^{\circ} \mathrm{CA}$ \\
\hline
\end{tabular}

Intake valve openings are changed by phasing camshaft in order to understand the emissions formation mechanism with various intake valve 
timing at steady operation condition.

Intake valve openings were controlled by retarding of $10^{\circ} \mathrm{CA}$ unit from $\mathrm{BTDC} 30^{\circ} \mathrm{CA}$ (valve overlap: $40^{\circ} \mathrm{CA}$ ) to TDC (valve overlap: $10^{\circ} \mathrm{CA}$ ) and the excess air ratio were varied by increments of 0.1 units from $\lambda=0.9$ (rich) to $\lambda=1.1$ (lean) while MBT spark timing is maintained.

The emission characteristics were analyzed by 3 types of an exhaust analyzer. THC and NOx were analyzed by a high speed gas analyzer (HFR400 and fNOx400) and particle emissions were measured by an ELPI.

\section{Results and Discussion}

3.1 The Characteristics of MAP and exhaust gas temperature

Figure 2 shows the characteristics of the intake MAP (Manifold Absolute Pressure) and exhaust temperature according to different intake valve timings. MAP sensor is installed at the point between intake port and throttle body. The k-type (3.5 mm) thermocouples were used to measure exhaust gas temperature and mounted at exhaust port.

To measure catalyst temperature, especially, a very thin k-type thermocouple of $0.5 \mathrm{~mm}$ is installed into the catalyst bed. MAP values were measured $394 \mathrm{hPa}$ (0.394 bar) at BTDC $30^{\circ} \mathrm{CA}$, $350 \mathrm{hPa}(0.350$ bar $)$ at BTDC $20^{\circ} \mathrm{CA}, 336 \mathrm{hPa}$ (0.336 bar) at BTDC $10^{\circ} \mathrm{CA}$, and $339 \mathrm{hPa}(0.339$ bar) at TDC.

As the intake valve timing was retarded, the intake manifold pressure decrease because residual gas fraction flowed backward was low through the intake valve with reduced valve overlap. MAP at the TDC increased about $3 \mathrm{hPa}(0.003$ bar $)$ compared to BTDC $10^{\circ} \mathrm{CA}$ case.

This means that air supply might increase with more opening throttle valve to maintain a specific targeting engine speed and load.
As the result analysis, MAP was reduced about $58 \mathrm{hPa}\left(0.058\right.$ bar) from $40^{\circ} \mathrm{CA}$ to $20^{\circ} \mathrm{CA}$ of valve overlap, however, increased about $3 \mathrm{hPa}$ (0.003 bar) because of a little more intake air charging with increment of throttle position. This phenomenon can be explained with in-cylinder pressure.

The exhaust gas and catalyst temperature were increased as retarded from BTDC $30^{\circ} \mathrm{CA}$ to BTDC $10^{\circ} \mathrm{CA}$, however, comparing BTDC $10^{\circ} \mathrm{CA}$ with TDC, it was rarely changed.

Retarding the intake camshaft leads to the intake valve opening later so that valve overlap is reduced. The residual exhaust gas which has not already left the cylinder is a little back flow into the intake manifold by ascending piston compared to advanced opening of intake valve during exhaust stroke.

The decreased residual gas content in the freshly induced in $\mathrm{A} / \mathrm{F}$ mixture affects combustion process so that it leads to higher peak temperatures.

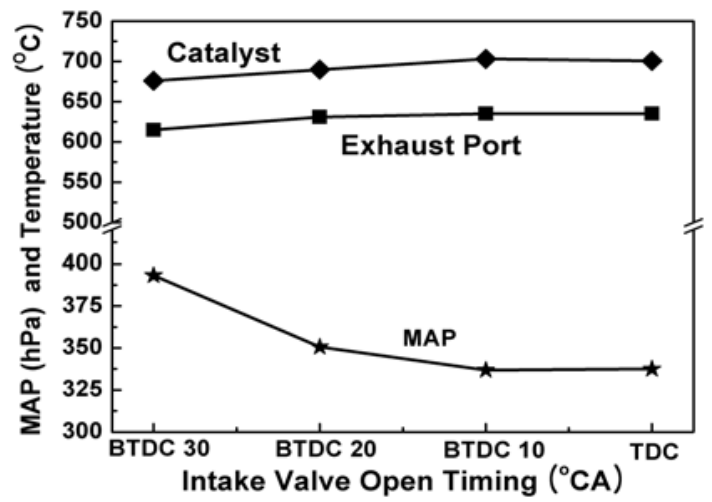

Figure 2: Effect of intake valve timing on the MAP and temperature $(\lambda=1.0$, injection pressure: 3.5bar)

\subsection{Combustion analysis}

Figure 3 indicates the in-cylinder pressure traces which were measured at No.1 cylinder on the various intake cam phasing. A combustion analyzer using a spark plug type pressure sensor was used 
for analyzing combustion characteristic. In-cylinder pressure was measured 200 cycles and averaged.

The value of peak cylinder pressure was 22.8 bar at BTDC $10^{\circ} \mathrm{CA}$ and 21.5 bar at TDC. As mentioned at MAP result discussion, a little increment of MAP by intake air charging did not have a strong influence on the combustion phenomena.

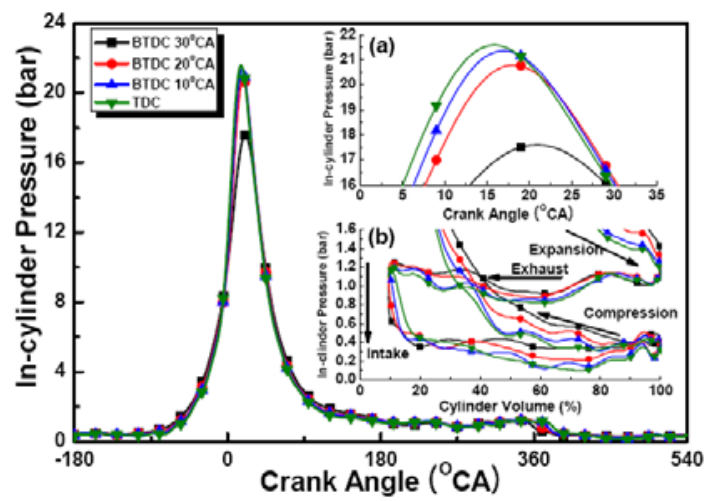

Figure 3: Comparison of in-cylinder pressure with IVO ( $\lambda=1.0$, injection pressure: $3.5 \mathrm{bar})$

\subsection{THC, NOx, and PM emissions}

Sampling probes for measuring THC and NOx were inserted into the center of upstream of catalytic converter. Effects of the fuel injection pressures and intake valve openings on the THC and NOx emission characteristics are represented in Figure 4 and Figure 5.

As the intake valve timing was retarded from BTDC $30^{\circ} \mathrm{CA}$ to TDC, THC levels were increased from about $8,900 \mathrm{ppmc}$ to $10,500 \mathrm{ppmc}$ at 3.5 bar, $\lambda=0.9$ and from about $4,270 \mathrm{ppmc}$ to 4,820 ppmc at 5.0 bar, $\lambda=0.9$. Comparing with injection pressures, THC levels were reduced about $55 \%$ at 5.0 bar.

Advanced opening of the intake valve leads to increased valve overlap so that unburned and burned gas mixture generated at the previous cycle flowed back into intake manifold.

The residual gases were then induced into the cylinder again with fresh air-fuel mixture and burned during combustion process. Therefore, unburned gases were decreased by burning at next cycle, which affect to the reduction of THC emission levels.

The increased residual gas in the freshly induced in combustible mixture caused by advancing the intake camshaft plays an important role in combustion process.

Moreover, the increased residual gas was worked on internal EGR (Exhaust Gas Recirculation) functioned as temperature falling off in a cylinder. The resulting lower peak temperatures lead to a reduction in NOx emissions. Early intake valve opening showed low NOx concentrations throughout all of lambda ratio.
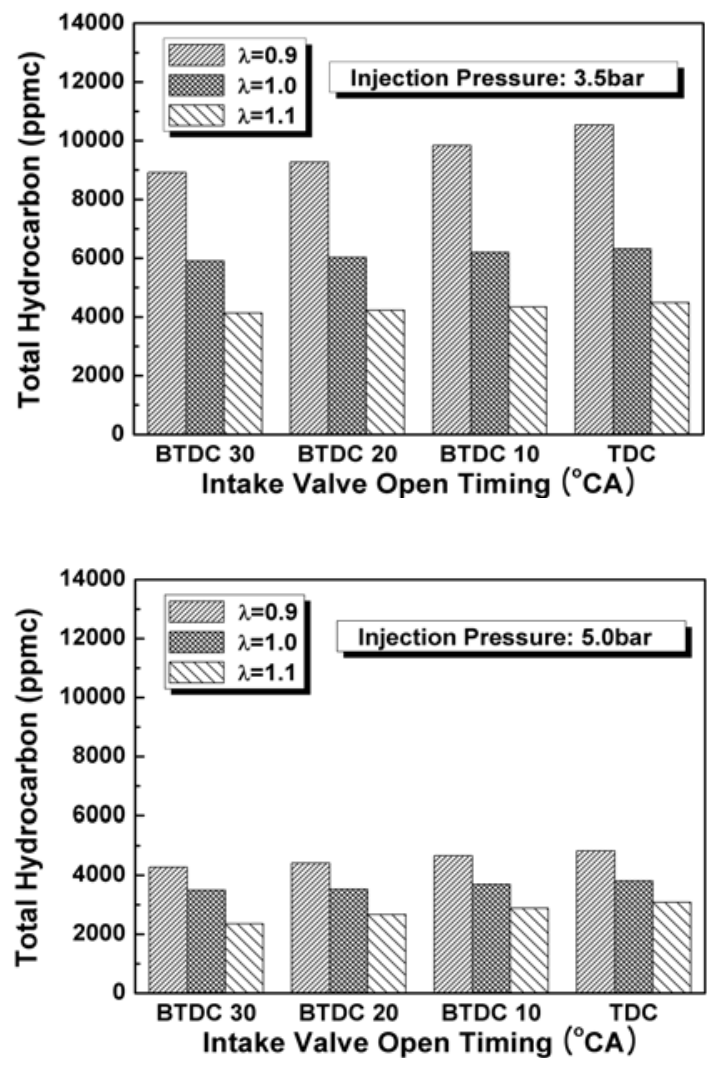

Figure 4: THC emission with different fuel injection pressures and intake valve timings 
As the valve overlap was decreased from $40^{\circ} \mathrm{CA}$ to $10^{\circ} \mathrm{CA}$, NOx emissions were increased from about $580 \mathrm{ppm}$ to $2,350 \mathrm{ppm}$ at $3.5 \mathrm{bar}, \lambda=1.0$ and from about $540 \mathrm{ppm}$ to $1,940 \mathrm{ppm}$ at $5.0 \mathrm{bar}, \lambda$ $=1.0$. NOx levels were reduced about $7 \% \sim 17 \%$ at 5.0 bar compared to 3.5 bar condition.

Since the low peak pressure by the advanced intake valve timing contributed to lower peak burned gas temperature and leaded to decrease NOx formation rates.
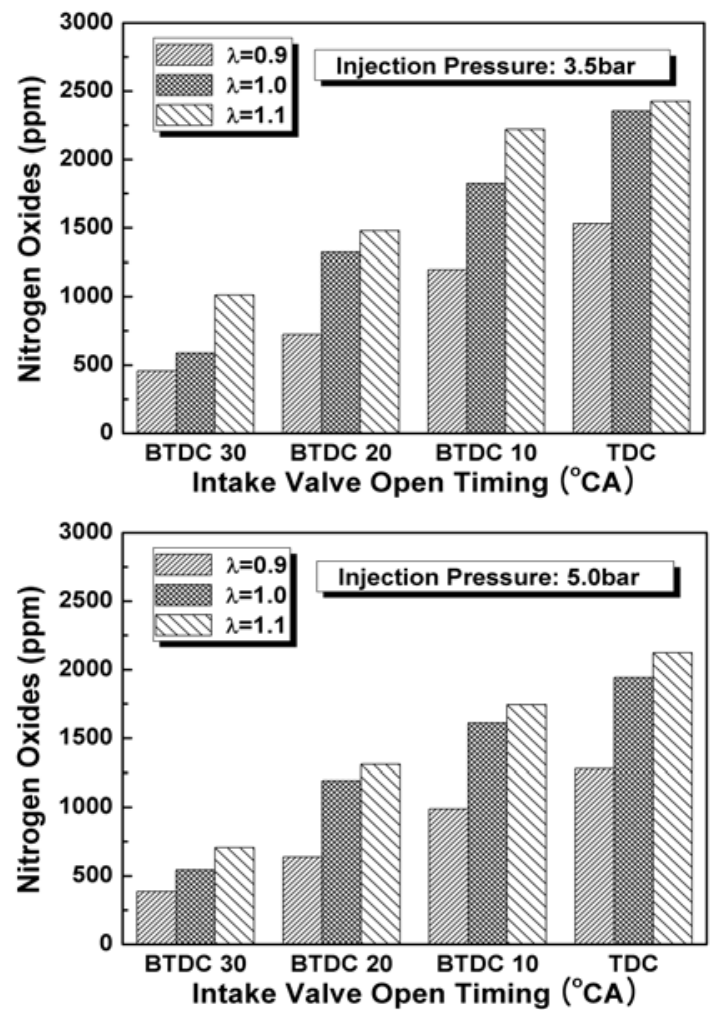

Figure 5: NOx emission with different fuel injection pressures and intake valve timings

Figure 6 shows the results of PM number concentrations with various intake valve timings and different fuel injection pressures. PM size distributions are generally classified into trimodal. The three modes are considered as the nucleation, accumulation and coarse mode.
The nucleation mode is typically composed of nanoparticles in the 5 50 nm diameter range. This mode is made-up to volatile organic and sulfur compounds formed at exhaust dilution and cooling process.

The accumulation mode ranged from $50 \sim 1,000$ $\mathrm{nm}$ usually consists of particles that have been deposited on cylinder wall and exhaust system surfaces. Finally, the coarse mode rarely emitted in internal combustion engine is composed of particles which have diameters greater than $1,000 \mathrm{~nm}$ [7].
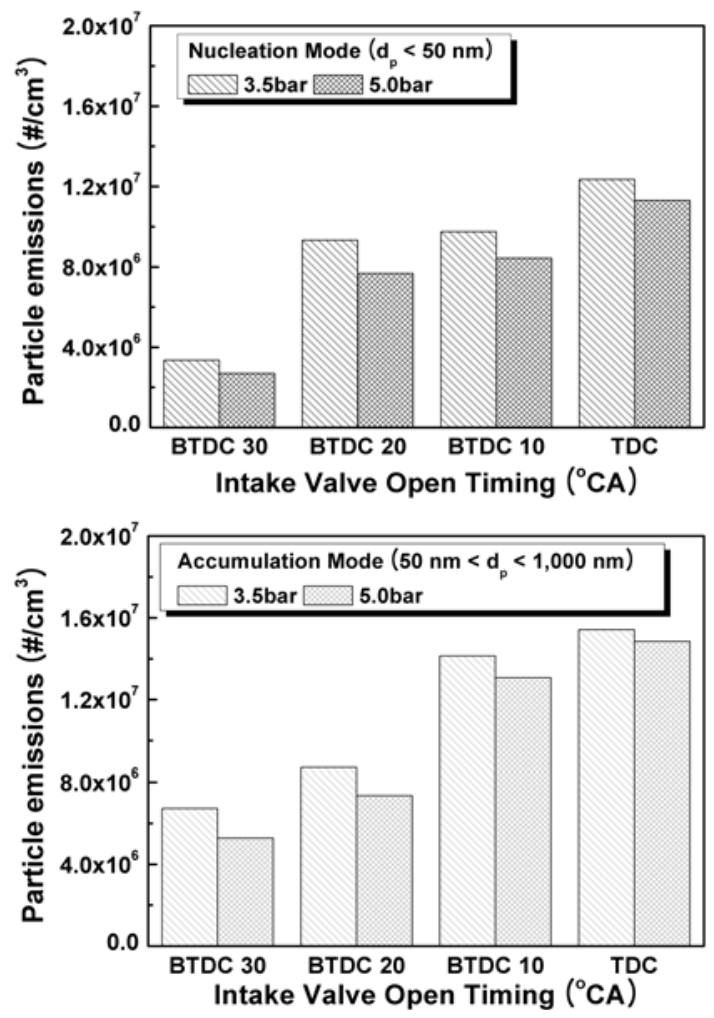

Figure 6: Particle emission with different fuel injection pressures and intake valve timings

PM size measured in this experiment was bi-modal which consist of the nucleation and accumulation mode. PM number concentrations were analyzed about $10^{6}$ particles $/ \mathrm{cm}^{3}$ orders at 3.5 bar and 5.0 bar. 


\section{Conclusions}

The experimental investigations for intake valve openings and fuel injection pressure were implemented to understand emission formation mechanism as well as particle size and number concentrations from a gasoline engine at part load condition. Based on these analyses, the major following conclusions can be summarized:

1. In-cylinder pressure was a few raised according to the intake valve late opening, however, effect of retarded valve timing on the combustion phenomena was slight. The exhaust gas and catalyst temperature were increased as the valve overlap was reduced. Retarding the intake camshaft affected the reduction of residual gas.

2. THC and NOx emissions were decreased as intake cam phasing was advanced at 3.5 bar and 5.0 bar. When the fuel was injected with condition of 5.0 bar at all of valve overlap ranges, high pressure injection showed the results that THC levels were reduced by 55\%. NOx concentrations were diminished about $75 \%$ as valve overlap was extended at without regard to injection pressure

3. In case of bi-modal type, PM emissions were analyzed about $10^{6}$ particles $/ \mathrm{cm}^{3}$ orders at $3.5 \mathrm{bar}$ and 5.0 bar under the part load condition. Comparing with fuel injection pressures, PM concentrations were reduced at high pressure injection of 5.0 bar condition. The magnitude of PM emissions was smaller when intake valve opening time was early.

\section{References}

[1] R. R. Jonathan, Z. S. Filipi and D. N. Assanis, "Transient diesel emission: Analysis of engine operating during a tip-in,” SAE Technical Paper, 2006-01-1151, 2006.

[2] R. F. Sawyer (Chairman of CARB), Keynote speech in 17th CRC On-Road Vehicle Emission Workshop 2007.
[3] F. Zhao, "Technologies for near zero emission gasoline-powered vehicles," SAE Handbook, pp. 407, 2007.

[4] G. B. Parvate-Patil, H. Hong and B. Gordon, "An assessment of intake and exhaust philosophies for variable valve timing," SAE Technical Paper, 2003-32-0078, 2003.

[5] C. Landerl, J. Liebl, R. Hofmann and T. Melcher, "The BMW SULEV concept: uncompromised emissions reduction, advanced engine design and performance," Proceedings of the Global Powertrain Conference (GPC), 2003.

[6] K. David and H. Simone, "Mechanism of particulate matter formation spark ignition engines. 1. Effect of engine operating conditions," Environmental Science and Technology, vol. 33, pp. 3957-3967, 1999.

[7] D. B. Kittelson, "Engines and nanoparticles: A review,” Journal of Aerosol Science, vol. 29, pp. 575-588, 1998.

\section{Author Profile}

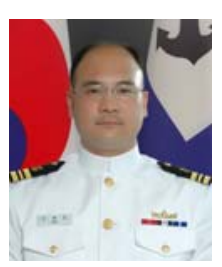

\section{Hyung-Min Lee}

Lieutenant Commander Hyungmin Lee, is currently assigned as Professor of Naval Ship Propulsion System Engineering at Republic of Korea Naval Academy, Jinhae, Gyeongnam. He received Ph.D. as Mechanical Engineering from Korea University in 2009.

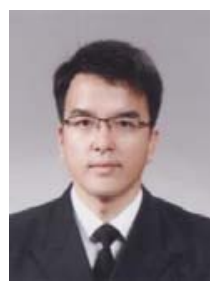

\section{Yeon-Hwan Jeong}

Lieutenant Commander Yeonhwan Jeong is currently assigned as Professor at Republic of Korea Naval Academy, Jinhae, Gyeongnam. He received Ph.D. as Naval Architecture and Ocean Engineering from Seoul National University in 2010 . 